\title{
Babbling of an Infant with a Repaired Cleft Lip: A Case Study
}

\author{
Carol Brenner and Karen Levin
}

Department of Speech Pathology and Audiology

University of the Witwatersrand

\begin{abstract}
The infant born with a cleft lip is faced with risk factors that threaten the development of speech-language skills. The earlier the age of identification and management of the developmental delay, the better the outcome. The attainment of the mature syllable is considered to be a critical measure of babbling competency. This single case study aimed to determine whether the formedness of the syllable in babbling would be affected by the cleft lip repaired prior to the onset of meaningful speech. Three samples of babbling in a naturalistic environment were video-recorded. Data was analysed following the principles of infraphonology, employing a perceptually-based method. A profile of infraphonological features was obtained. Results showed that the development of the mature syllable was attained. The results support the theories that babbling is a robust phenomenon. Clinical and research implications are discussed.
\end{abstract}

\section{OPSOMMING}

' $n$ Baba wat met ' $n$ gesplete lip gebore is, vertoon 'n risiko om vertraagde spraak-en taal-ontwikkeling te vertoon. Hoe vroeër die identifikasie en regstelling van hierdie ontwikkelingsagterstand geskied, hoe meer suksesvol sal die uitkoms wees. Die bemeestering van die lettergreepstruktuur word beskou as ' $n$ noodsaaklike maatstaf vir babbel-bevoegdheid. Die doel van hierdie studie was om te bepaal of die ontwikkeling van die lettergreepstruktuur beinvloed sal word deur die herstel van ' $n$ gesplete lip voor die ontwikkeling van betekenisvolle spraak. Drie afsonderlike spraakmonsters is met behulp van videokassetopnames in natuurlike omstandighede ontlok. Die data is geanaliseer deur middel van ' $n$ perseptuele metode en toepassing van infrafonologiese beginsels. ' $n$ Infrafonologiese profiel is saamgestel. Uit die resultate blyk dit dat die ontwikkeling van die lettergreepstruktuur wel bereik is. Die resultate ondersteun die teorieë dat babbel 'n kragtige ontwikkelingsverskynsel is. Kliniese en navorsingsimplikasies word bespreek.

KEY WORDS: cleft lip, canónical babbling, infraphonology, precursor vocalisation, syllable structure.

\section{INTRODUCTION}

Few infants with cleft lip without any other defect are referred to the speech-language pathologist (SLP) because of the apparent insignificance of the repaired structural abnormality. According to Lohmander-Agerskov, Soderpalm, Frieds, Persson and Lilja (1994), the extent of the cleft is directionally proportional to the speech abnormality. Research has shown that, in general, children born with clefts of the lip and/or palate have a slower overall rate of development when compared with their non-cleft peers (Savage, Neiman \& Reuter, 1994). By all measures, a cleft lip is a mild structural defect (Bzoch, 1989), which implies that a speech abnormality in a child with a cleft lip will be minimal, if present at all.

However, it is well recognised that speech-language development in children is vulnerable to a wide variety of risk factors (Rossetti, 1996). Infants born with cleft lips face an array of risk factors. These include prolonged hospitalisation for surgery, feeding difficulties and poor bonding with the caregiver as a result of aesthetically displeasing physical features (Bzoch, 1989; Morris, 1989). Because of these primary and secondary factors, children with cleft lips are at risk for developmental speech delays. The early identification of speech-language delay has been advocated for many years because it has been established that the earlier any form of developmental delay is identified and intervention provided, the better the outcome (Rossetti, 1996).

Until recently babbling was not considered continuous with speech (Menn, 1992), but it is now widely accepted that it is directly and unequivocally related to later linguistic development (Kent \& Miolo, 1995). A number of studies have demonstrated differences in the babbling of infants at-risk for communication disorders (For example: Levin, 1999; O'Gara \& Logemann, 1988; Steffens, Oller, Lynch \& Urbano, 1992; Stoel-Gammon, 1989). The study of babbling in infants who are at risk for later speechlanguage development is critical because of the need for early identification and management of the delay.

Very few infant-assessment profiles include a comprehensive evaluation of babbling and the methodologies for the study of babbling are not well developed (Levin, 1999). For example, there is no consensus as to which measures of babbling are valid. Much research into babbling has made use of phonetic analysis of utterances but because the phonetic structure of babbling is immature, these studies 
may not be valid (Oller, Eilers, Steffens, Lynch \& Urbano, 1994). The syllable is one of the most critical notions that has been the centre of research on babbling. Most contemporary theories on phonology hold that the syllable is the criterion that defines the "speechiness" or the "essential auditory quality of speech" (Kent \& Miolo, 1995, p. 310). Furthermore, many researchers have proposed that the syllable appears to be the basic phonological unit that the infant uses to learn the structure of his phonological system (Kent \& Miolo, 1995; Stoel-Gammon, 1992).

Oller and his colleagues at the Miami State University have developed a system of analysing babbling based on the principles of what they have termed 'infraphonology' (Lynch, Oller \& Steffens, 1989; Oller, 1980; Oller, Eilers, Bull \& Carney, 1985; Oller et al., 1994, Oller \& Lynch, 1992). The infraphonological model provides an explicit characterisation of the infrastructure of the phonology system by specifying the nature of phonetically well-formed elements and the relations between them (Oller \& Lynch, 1992). The canonical syllable is defined by Oller \& Lynch (1992) as one minimal rhythmic unit. It is perceived by adult speakers as a wellformed syllable with at least one consonant, a full adult-like vowel and a normally rapid transition between them. Contrary to phonetic studies, within this model pre-canonical or underdeveloped syllables can be easily compared with wellformed mature speech (Oller \& Lynch, 1992).

Studies have shown that the development of the canonical syllable occurs despite the presence of factors that are known to affect speech-language development. Researchers such as Oller et al. (1994) and Pettito \& Marentette (1991) have described this as a result of the flexibility of the development of babbling. It would be valuable to assess the development of the canonical syllable in infants who have cleft lips to determine whether a structural abnormality in the prespeech period is a challenge to the theory of the robustness of babbling. It would also be of value to use babbling as a measure of early speech-language development for the identification of speech-language delay in the first months of life. This single case study aimed at evaluating the development of babbling, from an infraphonological perspective, of an infant with a repaired cleft lip. The study included an evaluation of the production of canonical syllables, marginal (immature) syllables and precursor vocalisations (such as growls and shrieks).

\section{METHODOLOGY}

\section{SUBJECT}

\section{Subject Selection Criteria}

Stringent criteria for selection were set to isolate the effects of the repaired cleft lip on babbling. Subject case history was obtained through completion of a detailed case history form (Department of Speech Pathology \& Audiology, University of the Witwatersrand) by the subject's mother, and followed by an interview. Paediatric and surgical records were accessed for medical information.

The subject was expected to be between the age of nine and eleven months, with a repaired cleft lip. By this age the normally developing child has developed canonical babbling (Oller et al., 1994). This means that at least $20 \%$ of the subject's syllables comprise at least one consonant, a full vowel and a rapid transition between them (Oller, 1980). It was expected that the repair to the lip had been performed preferably by 5 months of age, at which stage canonical babbling would not typically have begun.

The subject was required to have normal hearing and no family history of hearing loss because of the documented effects of hearing loss on babbling (Stoel-Gammon \& Otomo, 1986). Visual response audiometry and tympanometry was performed to determine hearing status. The subject was expected to come from a middle-to-high socio-economic background because differences in the babbling of infants from low socio-economic groups have been demonstrated (Oller et al., 1994). Socio-economic status was determined by the educational and professional status of the parents as in Oller et al. (1994).

\section{Description of the Subject}

The subject was 9 and a half months old at the time of testing and presented with a right-sided unilateral complete cleft lip at birth. An anatomical lip-plasty was performed at five months of age, with no complications. Length of hospitalisation was negligible. The subject's right nares was deviated after the repair, however the only surgery further recommended was for cosmetic purposes. It was confirmed that there was no additional cleft of the hard or soft palate and no other cranio-facial abnormalities were present. There was no family history of speech-language or hearing difficulties. Pregnancy and birth history were unremarkable. Primary caregivers were not concerned about any aspect of the subject's communicative or physical development and no feeding difficulties prior to or after surgery were reported.

\section{METHOD}

The study comprised the collection of data, training of raters, transcription of data and analysis of results.

\section{Collection of Data}

The subject was video-recorded at her home on three occasions, for half an hour at a time. Following Levin (1999), video-recordings as opposed to audio recordings allowed for accurate determination of when utterances were unintelligible as a result of a hand or object in the mouth. Recordings were made at the subject's home to allow for a more natural environment and typical interaction patterns. Three recordings were made because of the documented inter-sessional variability in the babbling of one child (e.g., Levin, 1999; Oller et al., 1985). Data was collected 'within 10 days to account for developmental factors.

The first author set up and controlled the equipment and was present as an undisguised participant at all three sessions (Shaugnessy \& Zechmeister, 1990)! A Sony Handycam CCD-F340E video-recorder was used to record the sessions.

Steffens et al. (1992) report that the amount of vocalisation can be influenced by the presence of an interlocutor. Each session therefore consisted of. 2 components:

a) The subject playing by herself with toys that made minimal noise (15 minutes).

b) The primary caregiver interacting naturally with the subject (15 minutes).

Vocalisation was encouraged using the subject's own age appropriate toys, smiling, eye contact and verbalisations on the part of the interlocutor (O'Gara \& Logemann, 1988). All data used for analysis was confirmed by the caregivers as being typical of the type of babbling patterns produced by the subject within a natural environment. 


\section{Training of Raters}

According to Steffens et al. (1992), after a period of training, adult listeners are consistent in judging vocalisations using infraphonological analysis. Studies have demonstrated this consistency in the Miami group's research (Lynch \& Oller, 1992; Oller et al., 1994; Lynch et al., 1989). A study conducted independently from this group of researchers determined that listeners could be trained within short periods of time in infraphonological analyses, with good consistency (Levin, 1999).

Three raters were selected all of whom had been trained phonetically. One of the raters had previous experience with infraphonology. The raters were trained by the second author who is familiar with infraphonology theory and analysis. Training comprised a single-day session where the raters were provided with theoretical background on infraphonology and introduced to concepts necessary for analysis. A home video-recording of the subject in a natural environment was used to demonstrate theoretical concepts. Training was considered complete when inter-rater reliability was $90 \%$ for utterances in this training sample (Oller et al., 1994).

All training and analysis employed a $35 \mathrm{~cm}$ Grundig T.V. monitor and a JVC HR-J727MS stereo video-recorder with audio signals routed through a 5 channel Pioneer VS * 505S AV system.

\section{Transcription of Data}

The three raters rated the audio-visual recordings of the subject as a group. This structure has been found to lessen the time needed for analysis and adds to reliability as it decreases the chance for error (Levin, 1999).

Data was coded according to the principle categories of infraphonology after Lynch et al., (1989) and recorded on an Infraphonological Analysis Profile (IFAP) which was developed by Levin (1999).

The IFAP comprises of 3 sections. The first is an analysis of utterances produced. Utterances are defined as vocalisations that "do not include a previously used arbitrary rule requiring that vocalisations be separated by a fixed duration of silence (e.g., 1 second)" (Steffens et al., 1992, p. 239). This definition allows the rater to use tacit awareness of phrasing and grouping of sounds and judgement is based on perceived "breath groups" regardless of the duration of the silence. According to Lynch et al., (1989) interobserver agreement improves when analysis is in accordance with this definition.

The second section of the IFAP is a checklist of precursor vocalisations (defined in table 1 ). These are included in infraphonological analysis since they are considered part of the infant's repertoire of speech-like sounds which employ the characteristics of timing, frequency and amplitude. They

TABLE 1: Definitions of infraphonological categories (After Lynch et al., 1989., Oller et al., 1985., Oller et al., 1994., Steffens et al., 1992)

\section{PRECURSOR VOCALISATIONS}

Squeals

Growls glottal fricative sequences|

\section{Yells}

Whispers

Raspberries

Clicks

Ingressive-egressive sequences

Syllable affricates and fricatives
Vocalisations at high pitch, usually falsetto, distinctly out of the range that would be typical in speech.

Vocalisations at low pitch, often in a creaky voice, distinctly out of the range that would be typical in speech.

Squeals and growls are considered to be explorations of pitch

Sequences wherein vowels or quasi-vowels occur in syllable-like sequences with glottal consonants, which require no formant transitions because there is no supraglottal articulation

Distinct from cries

Yells and whispers are considered explorations of amplitude

Labiolingual or labial trills and/or vibrants

Suction stops often occurring in clusters

These are viewed as explorations of the airstream mechanism

These are viewed as explorations of frication.

\section{SYLLABLE STRUCTURE CATEGORIES}

Quasi-resonant vowels (QRV)

Fully resonant vowels (FRV)

Marginal syllables (MS)

Canonical syllables (CS)
Vowel-like sounds produced with the vocal tract at rest and with normal phonation, considered developmentally primitive or less speech-like

Perceived as being produced with the vocal tract open, and with normal phonation, likened to vowels produced by adult speakers. The appearance of FRV's marks the beginning of the exploitation of the resonating potential of the vocal tract

These include at least one consonant, a full vowel, and a slow transition between them (typically longer than 120 milliseconds). They are considered developmentally primitive.

Perceived as well-formed syllables with at least one consonant, a full vowel, and a rapid transition between them,. They are considered to be prototypical units and are the basic building blocks of all languages. 
occur frequently in babbling and are significant in the development of speech (Kent \& Miolo, 1995).

The third section of the IFAP is a checklist of developmentally-primitive and well-formed syllables. The syllable structure categories all symbolise syllabic units with or without key features of well-formedness. The principle categories of syllable structure are defined in Table 1.

Inter-rater reliability was set at $90 \%$ agreement for canonical syllables (Oller et al., 1994). For all other features of the Syllable Structure acceptable inter-rater reliability was reduced to $85 \%$ (Oller et al., 1994). According to these same authors, precursor vocalisations may be categorised without reliability measures as coding is essentially inherent. This study did, however, include reliability measures for precursor vocalisations since infraphonology has had limited exposure outside Miami State University. By assessing the reliability of precursor vocalisations, it was possible to determine whether theoretical concepts in the literature were adequately explained to be understood and applied by the individual raters.

Good inter-rater reliability (Oller et al., 1994), for canonical and marginal syllables was obtained in sessions $1 \& 3$ (refer to Table 2 ). The comparatively poor inter-rater reliability in session 2 was attributed to the small number of these syllables recorded during the session. Inter-rater reliability was close to or $100 \%$ for all precursor vocalisations. The overall high levels of agreement indicate that infraphonological principles were reliably applied by the raters after a limited period of training.

\section{Analysis of Data}

\section{Well-Formedness Measures}

According to Steffens et al. (1992) ratios are more valuable than frequency counts in the broader background of the total number of syllables produced. The syllable structure categories all symbolising syllabic units with or without key features of well-formedness, were recorded in the total number of syllables produced on the IFAP. For each feature of the syllable structure a ratio was calculated by dividing the number of representative syllabic units by the total number of syllables within a sample (Oller et al., 1994). The canonical babbling ratio (CBR) is the measure against which phonetically well-formed utterances are judged and was considered the key ratio of this study. A CBR of 0.15 was considered the minimum ratio to evidence canonical syllables and a CBR of 0.2 assigned the child to the "canonical stage of babbling" (Oller et al., 1994).

\section{Precursor Vocalisations}

Frequency counts for precursor vocalisations were recorded for each session.

\section{RESULTS AND DISCUSSION}

The results will be presented in two sections. The first section will describe the utterance and syllable counts, and the analysis of the utterances and syllables that could not be analysed. These results are presented first because all results of the infraphonological analysis presented need to be evaluated against this background. The second section presents an analysis of the canonical syllables and the precursor vocalisations produced by the subject.

\section{ANALYSIS OF UTTERANCES AND SYLLABLE COUNTS}

Table 3 represents a frequency count for utterances and syllables produced in each of the three half hour recording sessions.

More than 70 utterances were produced in each of the three sessions of which only the first 70 were coded. This is the convention of the Miami group studies. Steffens et al.,

TABLE 2: Percentage inter-rater reliability for three sessions

\begin{tabular}{|l|c|c|c|}
\hline Feature & Session 1 & Session 2 & Session 3 \\
\hline Total utterance & 97 & 93 & 100 \\
Total syllables & 92 & 99 & 94 \\
\hline SYLLABLE STRUCTURES & & & \\
\hline Fully Resonant Vowel & 100 & 100 & 94 \\
Quasi-resonant Vowel & 93 & 89 & 89 \\
Canonical Syllable & 92 & 71 & 1 \\
Marginal Syllable & 85 & 67 & 92 \\
\hline PRECURSOR VOCALISATIONS & & & 85 \\
\hline Squeal & 95 & 100 & $\cdot$ \\
Yell & 100 & 100 & 100 \\
Whisper & - & - & 100 \\
Trill & 100 & - & - \\
Click & 100 & - & 100 \\
Ingressive-egressive sequence & 100 & 100 & - \\
Affricate & 100 & - & 100 \\
Fricative & - & - & 75 \\
\hline
\end{tabular}


(1992) found that neither normally developing nor children with Down Syndrome always produced this minimum in a half-hour recording session. Levin (1999) reported that year old infants with cerebral palsy also frequently did not produce as many as 70 utterances within the same time frame.

There is no normative data on what is considered an appropriate amount of babbling within a period of time. Oller et al. (1994) defined the number of utterances per minute as a measure of volubility while other researchers value different measures such as "mean babbling level" (Stoel-Gammon, 1989), and multiple measures (e.g.: Jenkins, Boggild-Anderson, Schmidt, Ankerhus \& Hansen, 1988). There certainly appears to be a positive correlation between the amount of vocalisation and subsequent speech and language development (Stoel-Gammon, 1992). It is clear that there is no consensus in the literature on measuring volubility. The importance of volubility in the subject is unknown and since the infraphonological framework does not include this measure, inferences from this single case study could not be made.

Inter-sessional variability regarding total number of syllables produced was marked (See Table 3). In session 3 , almost double the number of syllables were recorded in a sample of 70 utterances than were in session 2 . Kent (1992) ascribes inter-sessional variability to the developing motor pattern not yet well established in the infant, as well as to interpersonal preferences. Variability in babbling has been described by many authors (e.g.: Kent, 1992; StoelGammon, 1989), and the inter-sessional variability of the present study provides a strong rationale for the collection of at least three samples of data within a given time period.

During session 3 the subject produced reduplicative sequences that were deliberately taught by her caregivers. Sequences were categorised by repetitive lateral movements of the tongue from side to side of the mouth. The consonant in the sequence sounded like an $/ /$ but was perceived as a marginal syllable and was produced frequently in this session. Each occurrence of this marginal syllable had to be counted in accordance with the infraphonological framework. This explains the relatively high number of both total syllables and marginal syllables produced in session 3 .

The IFAP was designed to include a count of utterances that were produced with a hand or toy in the mouth to prevent invalid codings due to sound distortions from external obstructions. This behaviour occurs frequently in infants. Stark (1980) describes babbling as the satisfaction of a need for sensory and mọtor stimulation. By placing her hand in her mouth, the infant was pairing the sensory input with motor stimulation (Morris, 1989). Hands-in mouth occurred in sessions 1 and 2 (Refer to Table 3). Although the use of visual recordings can influence the rating of essentially auditory-perceptual methodology, visual information is critical for the validity of codings. Many babbling studies have not made use of videorecordings (e.g.: Grunwell \& Russell, 1987; LohmanderAgerskov et al., 1994).

\section{INFRAPHONOLOGICAL ANALYSIS}

Table 4 illustrates the frequency counts and ratios of the infraphonological features in the three sessions.

\section{Canonical Babbling Ratio}

The subject produced a Canonical Babbling Ratio (CBR) of greater than 0.20 in sessions 1 and 3 . The relatively low CBR in session 2 was attributed to personal and environmental factors. It is clear that the subject was able to produce canonical syllables and her CBR was sufficient to assign her to the canonical babbling stage. The repaired cleft lip thus had no effect on the development of the syllable. Results are typical of a normally developing child (Kent \& Miolo, 1995). It is interesting that the infraphonological model excludes $/ \mathrm{w} /$ and $/ \mathrm{h} /$ from the definition of a canonical syllable because of the slow formant transitions. As a result, frequently occurring phonemes in this study had to be excluded from canonical syllable counts.

According to Oller (1980) the quasi-resonant vowel is the most commonly used non-vegetative vocalisation type across the stages of babbling even though fully resonant nuclei may be used from around 4-6 months. The subject used predominantly quasi-resonant vowels in session 2 where she was preoccupied with ornamental birds and imitated the interlocutor. It is possible that although she showed an ability to produce fully resonant vowels and canonical syllables, her choice of the use of quasi-resonant vowels in this session was personal.

In sessions $1 \& 3$, for every canonical syllable, at least 2 marginal syllables were produced. This was not unexpected even at the stage of canonical babbling. According to Steffens et al. (1992), marginal syllables persist beyond this stage of babbling until the child is at least 2 years old. The fact that this ratio was not reflective of session 2 was once again attributed to intrapersonal variability.

\section{Precursor vocalisations}

The subject did not produce growls, glottal stop sequences, glottal fricative sequences or raspberries. There was some consistency in the production of other precursor vocalisations across sessions (see Table 4), but intersessional variability was evident. Variations between the

\section{TABLE 3: Frequency counts of Utterances and Syllables produced per session}

\begin{tabular}{|l|c|c|c|}
\hline Feature & Session 1 & Session 2 & Session 3 \\
\hline Total utterances analysed & 70 & 70 & 70 \\
Undecided utterances & 2 & 5 & 1 \\
Analysable utterances & 62 & 58 & 68 \\
Unanalysed utterance (technical) & 0 & 2 & 1 \\
Hands-in-mouth & 6 & 5 & 0 \\
Total syllables & 105 & 98 & 181 \\
\hline
\end{tabular}


frequency of production of different precursor vocalisations have been reported in studies of high-risk populations such as premature infants (Oller et al., 1994) and hearing impaired infants (Oller et al., 1985) and in normally developing children (Oller et al., 1994). Oller et al. (1994) offer that this is because any individual plays with a sound repetitively and after a period of time excludes it from the babbling repertoire and selects other sounds with which to experiment. The reduced number of precursor vocalisations relative to the number of syllable structure features recorded in each session is indicative of the subject's progression towards mature speech (Oller \& Lynch, 1992). It is expected that with age there is a decrease in the production of precursor vocalisations as they begin to lose their communicative function (Stoel-Gammon \& Otomo, 1986).

\section{CONCLUSIONS}

The subject developed canonical babbling age appropriately therefore demonstrating that the repaired cleft lip had no effect on the development of infraphonological features. The subject also produced a variety of precursor vocalisations demonstrating an ability to manipulate the components of frequency, amplitude and timing that comprise mature speech. This single case study suggests that in children with cleft lip and palate it is probably primarily the cleft palate that affects the development of the components of speech necessary for the production of canonical syllables. The consistency of this vocal development despite the structural abnormality illustrates the flexibility of the speech-learning mechanism, and reinforces the concept of babbling being a robust phenomenon. Larger samples and analyses of other mild structural oral-motor abnormalities (e.g. tongue-tie) are needed to reinforce the current findings.

The results suggest that the SLP need be more involved in the management of a child with a cleft lip when other risk factors (e.g. hearing loss) that predispose a child to speech or language disability co-exist with the cleft lip. The SLP may also assume a counselling role in informing caregivers that the structural abnormality, once repaired should not affect babbling and speech. In this vein, since speech is one of the key measures by which the success of surgical repair is evaluated (Bzoch, 1989), infraphonological analysis pre- and post-surgery may be of value as most repairs will be completed before the child is able to produce adult syllables. Assessments of babbling should be included in developmental assessments which need be at regular intervals to monitor the child's development over time.

It would seem that the infraphonological model is a useful starting point for the analysis of babbling, but is insufficient as it is to adequately provide predictive data. It is evident that infraphonology and the methodologies for the study of babbling are in themselves in their infancy, and like babbling, will take practice, time, feedback, and quantity to mature and become meaningful.

The analysis of babbling development in the cleft lip and/ or palate population is an area that warrants further exploration because of the importance of babbling for later speech-language development. This single case study was an attempt to add to the literature additional information concerning early vocal development in infants with cleft lips. Acoustic, phonetic and infraphonological studies are needed, and longitudinal data would be invaluable.

\section{REFERENCES}

Bzoch, K. R (1989). Communication Disorders Related to Cleft Lip and Palate (Third Edition). Boston: College-Hill Publications.

Grunwell, P., \& Russell, J. (1987). Vocalisations Before and After Cleft Palate Surgery: A Pilot Study. British Journal of Disorders of Communication, 22, 1-17.

Jenkins, T. S., Boggild-Anderson, B., Schmidt, J., Ankerhus, J., \& Hansen, E (1988). Perinatal Risk Factors and First Year Vocalisations: Influence on Preschool Language and Motor

TABLE 4: Infraphonological features: Frequency counts and ratios (in brackets)

\begin{tabular}{|c|c|c|c|}
\hline Feature & Session 1 & Session 2 & Session 3 \\
\hline SYLLABLE STRUCTURE & & & $\vdots$ \\
\hline Fully Resonant Vowels & $4(0.03)$ & $3(0.03)$ & $36(0.20)$ \\
\hline Quasi-resonant Vowels & $15(0.14)$ & $82(0.84)$ & $27(0.15)$ \\
\hline Canonical Syllables & $27(0.26)$ & $7(0.07)$ & $38(0.21)^{\prime}$ \\
\hline Marginal Syllables & $59(0.56)$ & $6(0.06)$ & $80(0.44)$ \\
\hline \multicolumn{4}{|l|}{ PRECURSOR VOCALISATIONS } \\
\hline Squeal & 20 & 11 & 14 \\
\hline Yell & 7 & 4 & 8 \\
\hline Whisper & 0 & 0 & 1 \\
\hline Trill & 2 & 0 & 0 \\
\hline Click & 1 & 0 & 1 \\
\hline Ingressive-egressive sequence & 10 & 2 & 0 \\
\hline Syllable affricate & 2 & 0 & 4 \\
\hline Syllable fricative & 0 & 0 & 1 \\
\hline
\end{tabular}


Performance. Developmental Medicine and Child Neurology, 30, 153-161.

Kent, R. D. (1992). The Biology of Phonological Development. In Ferguson, C.A., Menn, L., \& Stoel-Gammon, C. (Eds.), Phonological Development: Models, Research, Implications. Maryland: York Press.

Kent, R. D., \& Miolo, G. (1995). Phonetic abilities in the First Year of Life. In Fletcher, P., \& McWhinney, B. (Eds.), Handbook of Child Language. Oxford: Blackwell.

Levin, K. (1999). Babbling in Infants with Cerebral Palsy. Clinical Linguistics and Phonetics, 13 (in press).

Lohmander-Agerskov, A., Soderpalm, E., Frieds, H., Persson, E., \& Lilja, J. (1994). Pre-Speech in Children with Cleft Lip and Palate or Cleft Palate Only: Phonetic Analysis Related to Morphologic and Functional Factors. Cleft Palate-Craniofacial Journal, 31, 4, 271-279.

Lynch, M. P., Oller, D. K., \& Steffens, M. (1989). Development of Speech-Like Vocalisations in a Child with Congenital Absence of Cochleas: The case of Total Deafness. Applied Psycho. linguistics, 10, 315-333.

Menn, L. (1992). Building our Own Developmental Phonology Comes of Age. In Ferguson, C.A., Menn, L., \& Stoel-Gammon, C. (Eds.), Phonological Development: Models, Research, Incplications. Maryland: York Press.

Morris, S. E. (1989). Development of Oral-Motor Skills in Children. Dysphagia, 3, 135-154.

O'Gara, M. M., \& Logemann, J. A. (1988). Phonetic Analyses of the Speech Development of Babies with Cleft Palate. Cleft Palate Journal, 25, 2, 122-134.

Oller, D. K. (1980). The Emergence of the Sounds of Speech in Infancy. In Yeni-Komshian, G. H., Kavanagh, J. F., \& Ferguson, C. A. (Eds.), Child Phonology: Volume 1. New York: Academic Press.

Oller, D. K., Eilers, R. E., Bull, D. H., \& Carney, A. E. (1985). Prespeech Vocalisations of a Deaf Infant: A comparison with Normal Metaphonological Development. Journal of Speech and Hearing Research, 28, 47-63.
Oller D. K., \& Lynch, M. P. (1992). Infant Vocalisations and Innovations in Infraphonology. In Ferguson, C.A., Menn, L., \& Stoel-Gammon, C. (Eds.), Phonological Development: Models, Research, Implications. Maryland: York Press.

Oller, D. K., Eilers, R. E., Steffens, M. L., Lynch, M. P., \& Urbano, R. (1994). Speech Vocalisations in Infancy: An Evaluation of Potential Risk Factors. Journal of Child Language, 21, 3358.

Pettito, L. A., \& Marentette, P. F. (1991). Babbling in the Manual Mode: Evidence for the Ontogeny of Language. Science, 251, 1493-1496.

Rossetti, L. M. (1996). Communication Intervention: Birth to Three. San Diego: Singular Publishing Group.

Savage, H. E., Neiman, G. S., \& Reuter, J. M. (1994). A Developmental Perspective on Assessment of Infants with Clefts and Related Disorders. Infant-Toddler Intervention: The Transdisciplinary Journal, 4, 221-234.

Shaugnessy, J. J., \& Zechmeister, E. B. (1990). Research Methods in Psychology (2nd Edition). New York: McGraw-Hill Publishing Company.

Stark, R. E. (1980). Stages of Speech Development in the First Year of Life. In Yeni-Komshian, G. H., Kavanagh, J. F., \& Ferguson, C. A. (Eds.), Child Phonology: Volume 1. New York: Academic Press.

Steffens, M. L., Oller, D. K., Lynch, M., \& Urbano, R. C. (1992). Vocal Development in Infants with Down Syndrome and Infants Who are Developing Normally. American Journal of Mental Retardation, 97, 235-246.

Stoel-Gammon, C (1989). Prespeech and Early Language Development of Two Late Talkers. First Language, 9, 207-224.

Stoel-Gammon, C (1992). Prelinguistic Vocal Development. In Ferguson, C.A., Menn, L., \& Stoel-Gammon, C. (Eds.), Phonological Development: Models, Research, Implications. Maryland: York Press.

Stoel-Gammon, C., \& Otomo, K. (1986). Babbling Development of Hearing Impaired and Normally Developing Subjects. Journal of Speech and Hearing Disorders, 51, 033-041. 